\title{
Transradial Retrieval of Broken Catheter After Complex PCI- A Nightmare
}

\author{
CM Shaheen Kabir ' , Saidur Rahman Khan ${ }^{2}$, Mashhud Zia Chowdhury ${ }^{3}$, M G Azam ${ }^{4}$, Hemanta I Gomes 5 , \\ Arifur Rahman ${ }^{6}$, Mah-Noor Jahan ${ }^{7}$
}

\begin{abstract}
Transradial access has now a days become a standard of care for percutaneous coronary angiography \& intervention. This approach has demonstrated significant reduction in bleeding rate, length of hospital stay and improvement in clinical outcomes when compared to the traditional TF approach. However this novel approach may lead to severe catheter kinking \& twisting and further manipulation may require unraveling the catheter and avoiding complication. The fracture of a guide catheter is an uncommon complication during percutaneous coronary intervention (PCI). It sometimes occurs during engagement of the right coronary ostium, when there is excessive twisting of the guide catheter. An interesting case of complete fracture of a $6 \mathrm{Fr}$ Ikari guide catheter in the brachial artery during transradial coronary intervention is presented.
\end{abstract}

Key words: complication, catheterization, retrieval, transradial access.

\section{INTRODUCTION:}

Transradial (TR) arterial access has become the default route for coronary procedures. ${ }^{1,2}$ This novel approach offers significant benefits over the traditional transfemoral (TF) approach including reduction of patient discomfort and major bleeding rate, shorter in-hospital stay with immediate mobilization of patients and its use has also been lately expanded for visceral and peripheral interventions. $^{3}$ However, the TR approach is technically more demanding due to the small caliber of the arm vessels. One of the issues that might occur with TR access is the fact that the access is associated with a higher rate of catheter looping or kinking over the traditional TF access site, which if not successfully treated may lead to catheter entrapment and vascular injury.

\section{CASE REPORT:}

A 58 years old hypertensive, diabetic, dyslipidaemic lady with prior history of PCI to OM \& RCA 2 years back was admitted with Unstable Angina. Her ECG revealed inferior ischaemia. Echo revealed normal LV systolic function. Coronary angiogram was done through transradial approach. There was subclavian tortuosity. Left anterior descending (LAD) artery had mild to moderate disease in its mid part. Stent in principal OM branch was patent. Dominant RCA had $70 \%$ stenosis in its mid part. Stent in distal RCA was also patent. PLV (Posterior Left Ventricular)

\section{Authors' information:}

${ }^{1}$ Dr. C M Shaheen Kabir, MBBS, MD, FSCAI, FACC, Associate Professor in Cardiology, Ibrahim Cardiac Hospital \& Research Institute, Dhaka-1000

${ }_{2}^{2}$ Dr. Saidur Rahman Khan, MBBS, MD-Card, PhD, FACC, Professor of Cardiology, Ibrahim Cardiac Hospital \& Research Institute, Dhaka-1000

${ }^{3}$ Dr. Mashhud Zia Chowdhury, MBBS, MD Card, DTCD, FACC, Professor Cardiology, Ibrahim Cardiac Hospital \& Research Institute, Dhaka-1000

${ }^{4}$ Dr. MG Azam, MBBS, MD, FSCAI, Professor of Cardiology, National Institute of Cardiovascular Diseases, Dhaka-1207

${ }^{5}$ Dr. Hemanta I Gomes, MBBS, D-Card, Assistant Professor in Cardiology, Ibrahim Cardiac Hospital \& Research Institute, Dhaka-1000

${ }^{6}$ Dr. Arifur Rahman, MBBS, D Card, Assistant Professor in Cardiology, Ibrahim Cardiac Hospital \& Research Institute, Dhaka-1000

${ }^{7}$ Dr. Mah-Noor Jahan, MBBS, DMU, Clinical Sonologist, Department of Radiology \& Imaging, Holy Family Red Crescent Medical College Hospital, Dhaka-1000

Address of Correspondence: Dr. CM Shaheen Kabir, cell:+8801817578389, e-mail:skabir67@yahoo.com 
branch had $80 \%$ proximal disease (Fig 1). So PCI to mid RCA and PLV branch was planned.

Guide catheter Ikari 1.5 5Fr \& Guide wire Sion blue were used. Predilataion balloon was $2.0 \times 8 \mathrm{~mm}$. PLV lesion was stented by $2.25 \times 12$ mm DES \& mid RCA lesion by another $2.75 \times 20 \mathrm{~mm}$ DES (Fig 2 \& 3). There was sudden displacement of guide catheter before taking final image due to deep inspiration by the patient (Fig 4). Final images revealed TIMI 3 flow in RCA after reengagement of Ikari guide catheter (Fig 5). There was partial dampening of pressure curve on monitor. Fluoroscopy revealed a tight knot within the right brachial artery along with the PTCA guide wire (Fig 6). Repeated clock \& anticlockwise rotation to unloop the knot were unsuccessful. So a long guide wire was advanced to untie the knot but failed (Fig 7). Guide catheter was broken into two pieces at the level of elbow (Fig 8). Proximal part of broken catheter was removed through the radial sheath. Snare catheter was used to retrieve the remaining broken segment but failed(Fig 9 \& 10). Finally a 6 Fr JR guiding catheter was advanced and the distal part of the broken catheter was captivated into the JR guiding catheter and was removed successfully through the ipsilateral radial approach (Fig 11-14). Contrast was injected from the sheath to confirm patency of brachial artery. The patient was discharged on day 2 in a stable state.

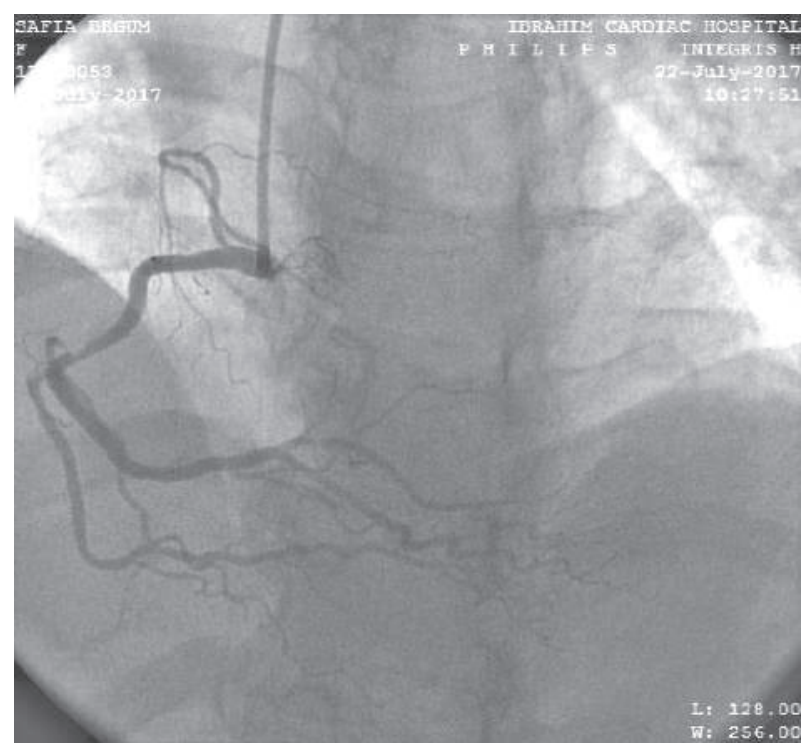

Figure 1: Right coronary artery angiography

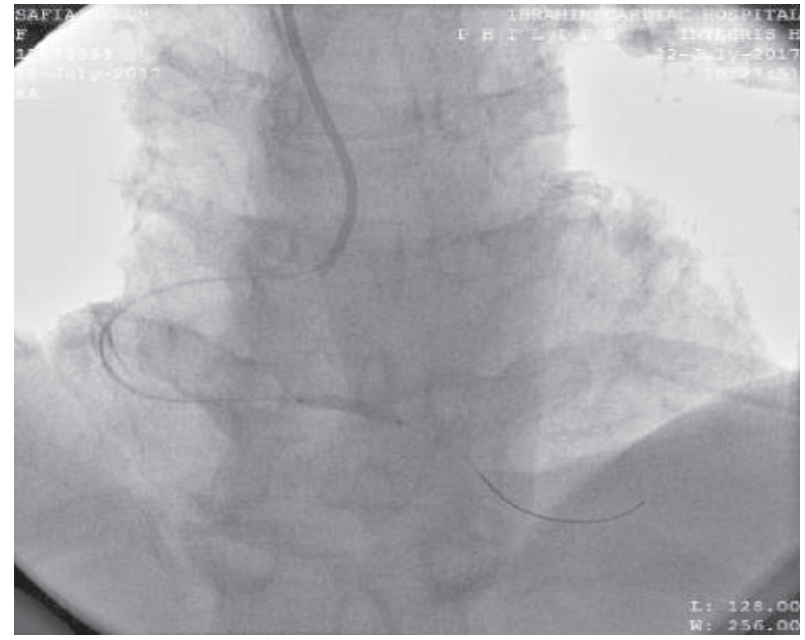

Figure 2 : PLV lesion was stented by $2.25 \times 12 \mathrm{~mm}$ DES

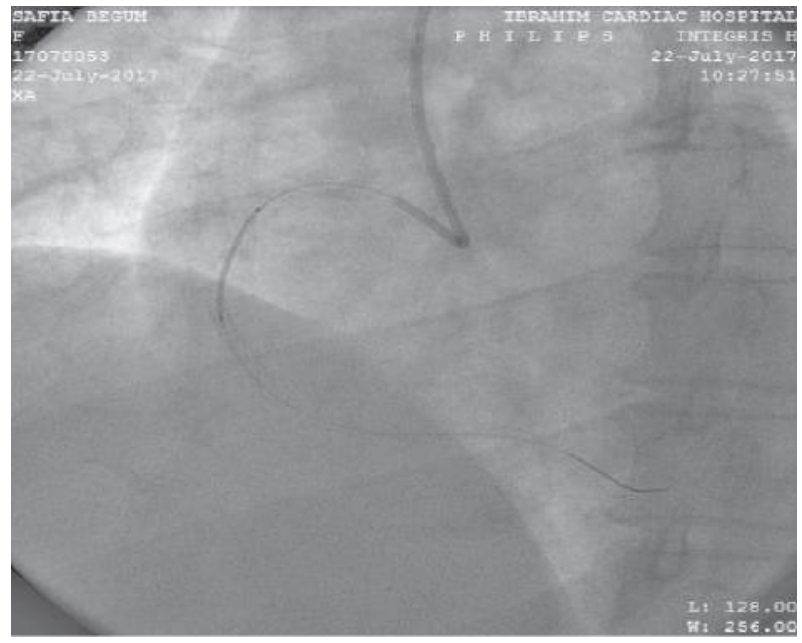

Figure 3 : Mid RCA lesion was stented by $2.75 \mathrm{X} 20 \mathrm{~mm}$ DES

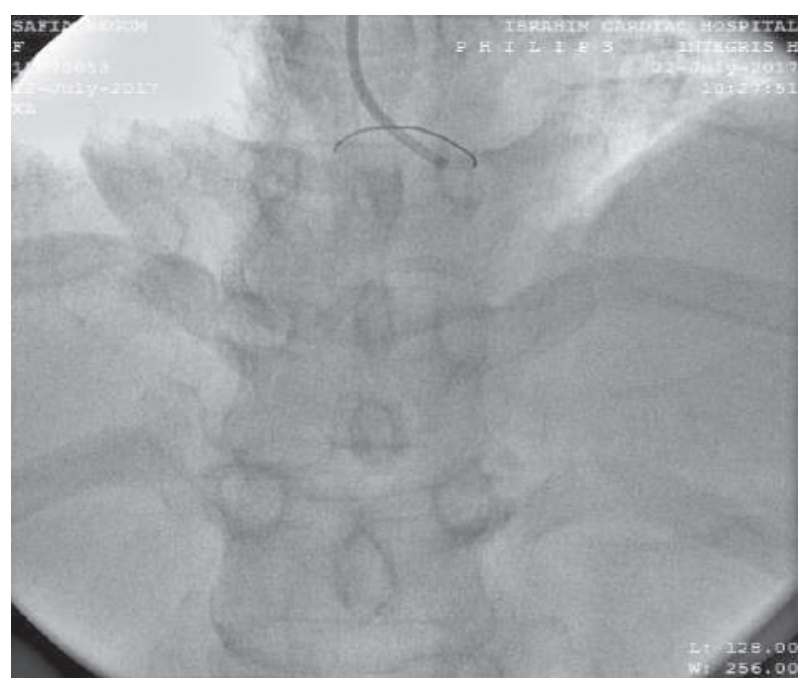

Figure 4 : Guide catheter was displaced before taking final image 


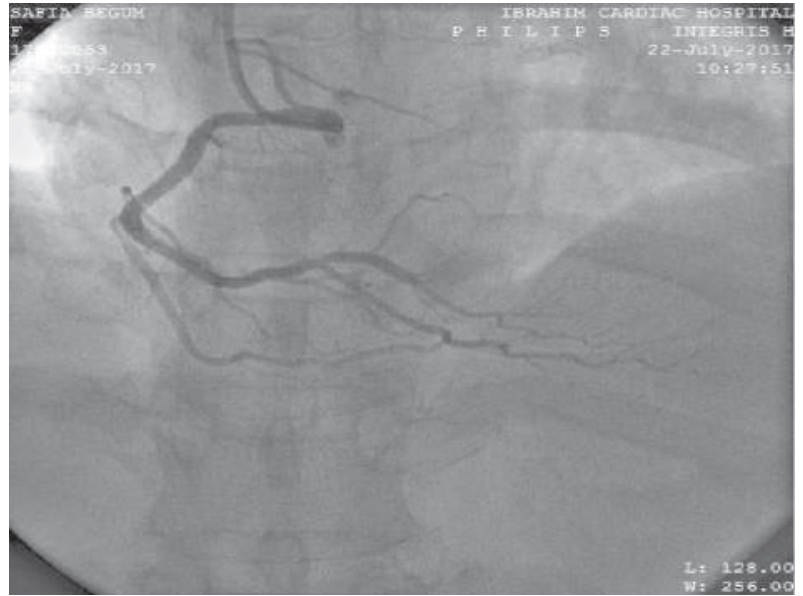

Figure 5 : Distal TIMI 3 flow in RCA after reengagement of guide catheter

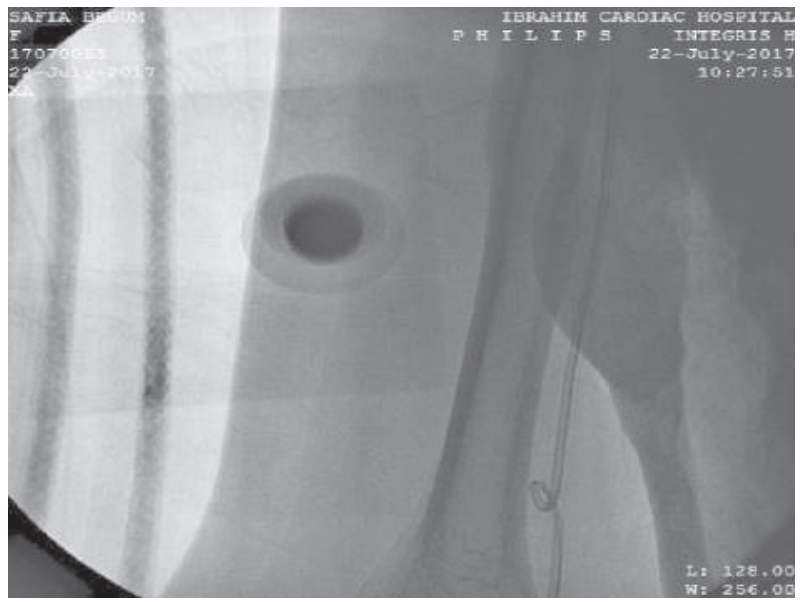

Figure 6 : Fluoroscopy revealed a tight knot within the right brachial artery along with guidewire inside the guide catheter

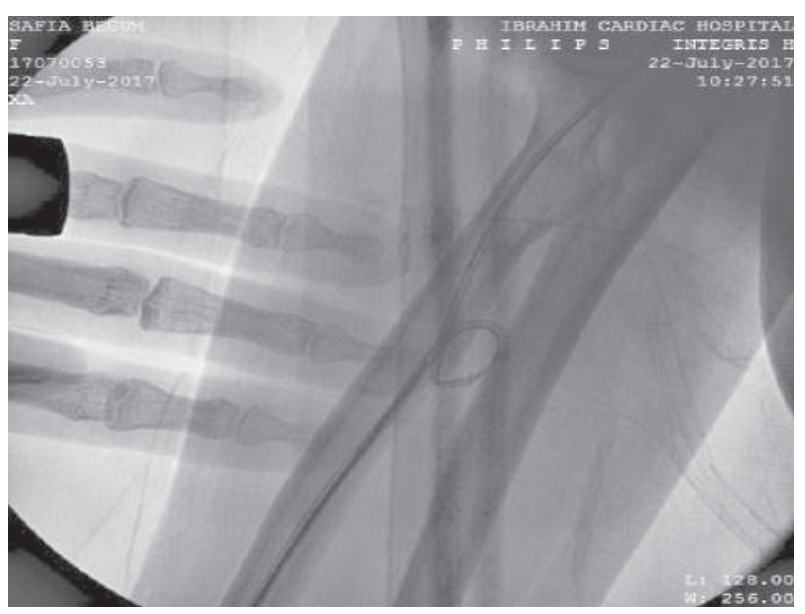

Figure $7:$ A standard wire was advanced to unravel the catheter knot

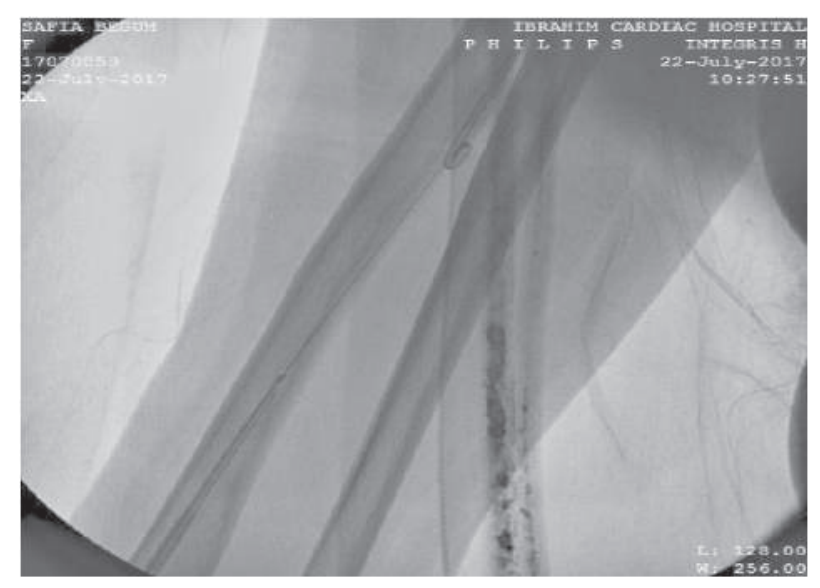

Figure 8: Complete fracture of the Ikari guide catheter into two pieces

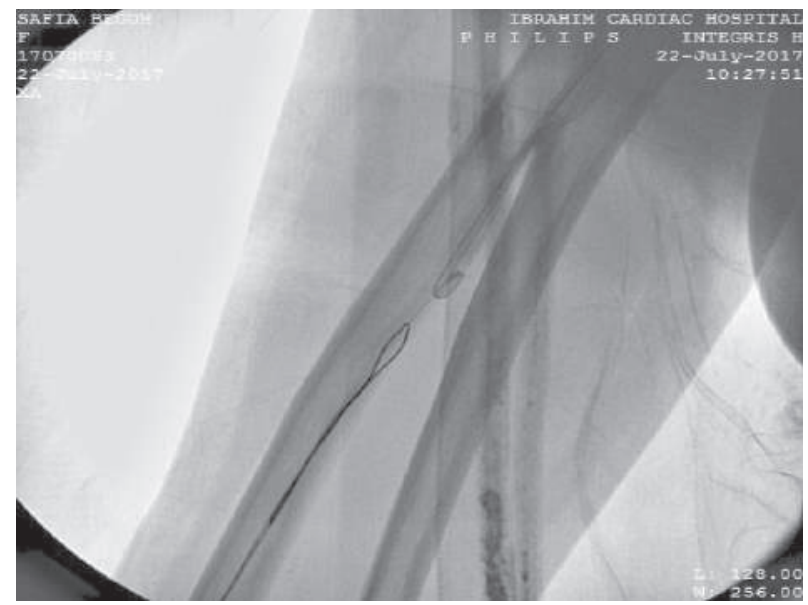

Figure $9:$ Attempt to snare the distal part of retained catheter using a snare

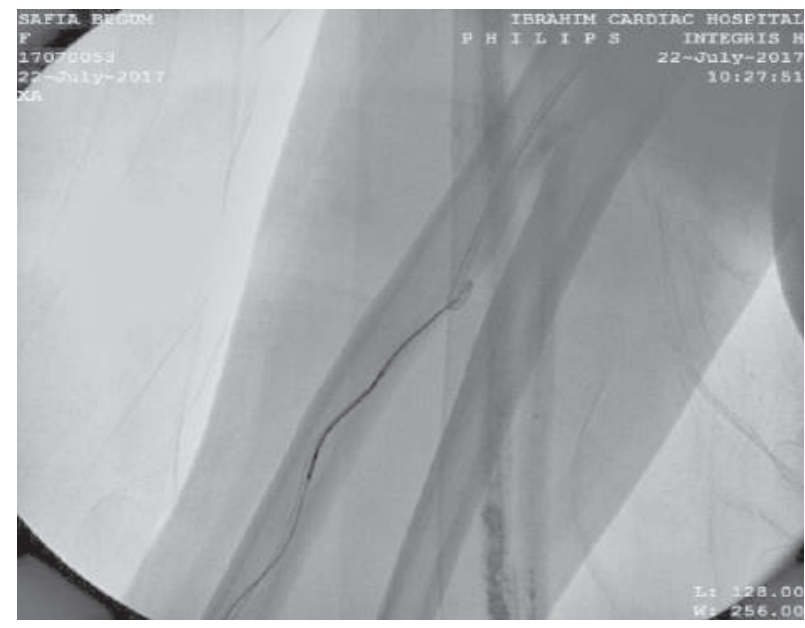

Figure 10 : Retrieval using a snare was attempted several times but failed. 


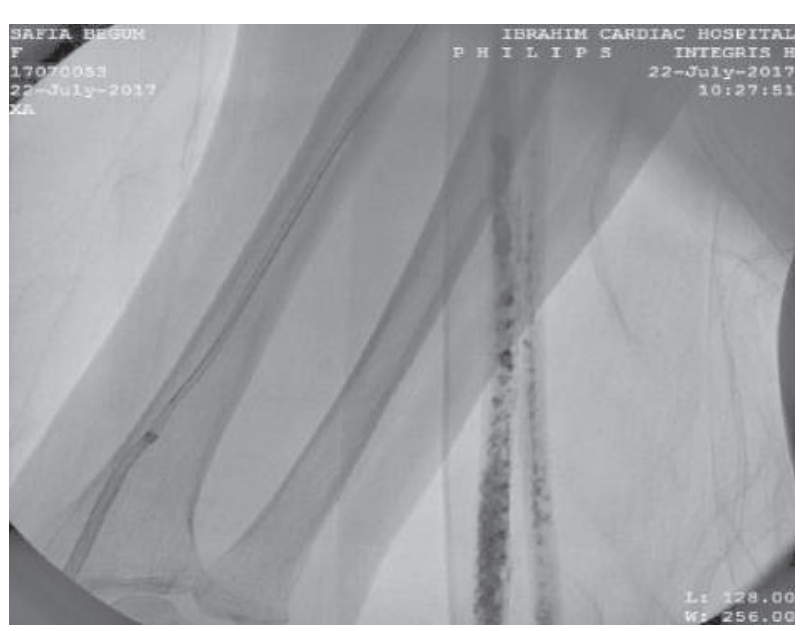

Figure 11 : Successful removal of distal part of the broken catheter using a 6 Fr guide catheter

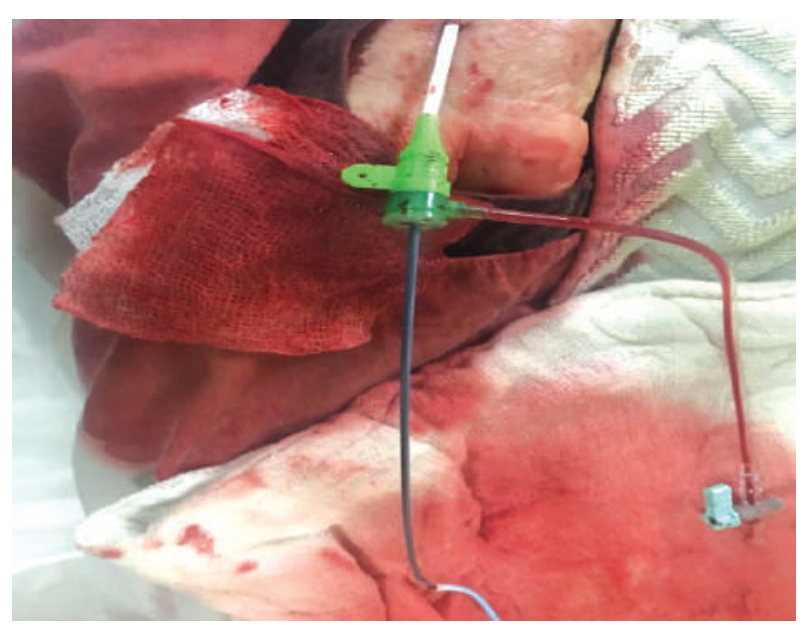

Figure 12 : Distal part of Ikari catheter was captivated into the JR guide catheter and was taken out

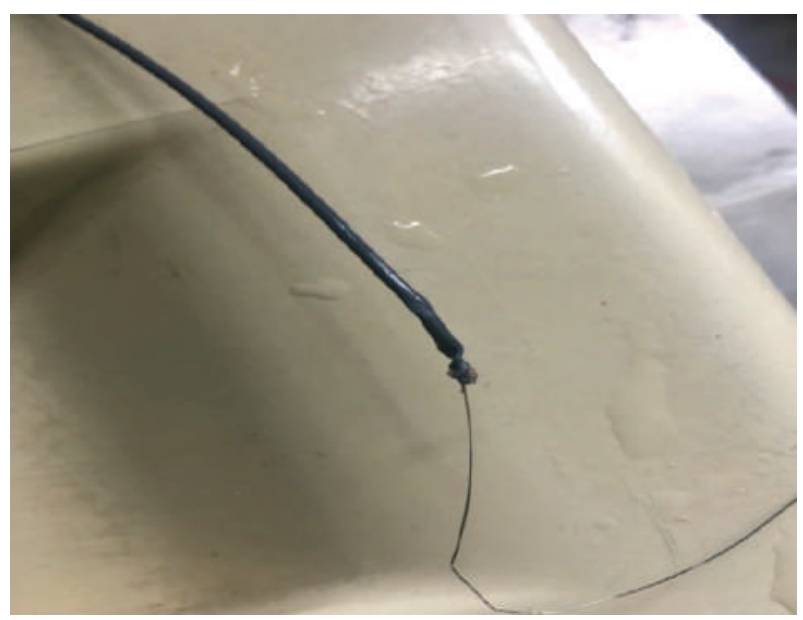

Figure 13 : Retrieved distal part of the catheter part with guidewire inside the guide catheter

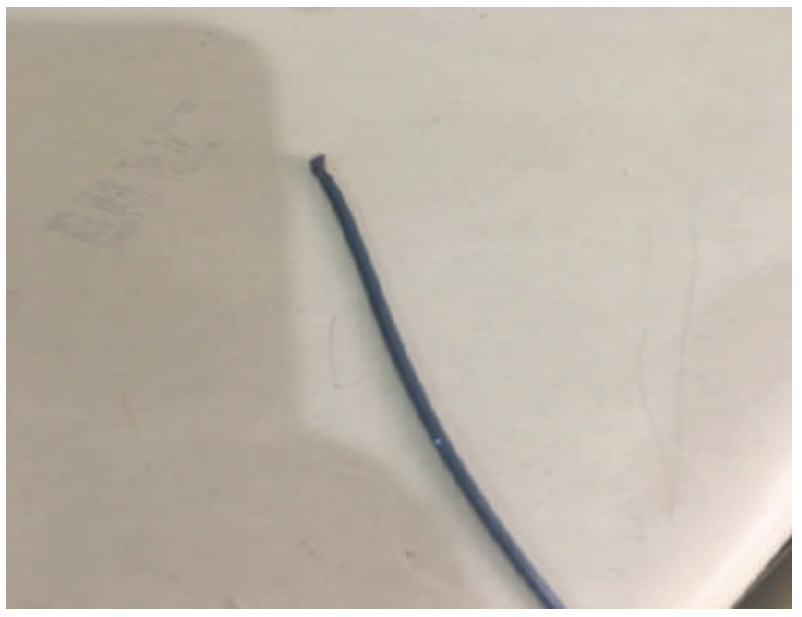

Figure 14 : Retrieved proximal part of the guide catheter

\section{DISCUSSION:}

TR access has now a days become a standard of care for percutaneous coronary angiography \& intervention. ${ }^{4,5}$ This approach has demonstrated significant reduction in bleeding rate, length of hospital stay \& improvement in clinical outcomes when compared to the traditional TF approach. ${ }^{6}$ However this novel approach may lead to severe catheter kinking \& twisting \& which may require further manipulation to unravel the catheter $\&$ avoid complication. ${ }^{7}$

The etiology of kinking/looping and potential entrapment of the catheter after a TR access is multifactorial: Excessive manipulation combined with significant vessel tortuosity results in increased resistance \& loss of one-to-one torque resulting in a higher chance of downstream looping $\&$ kinking. Forced manipulation to relieve the loop in the brachial or radial arteries increases the probability of vasospasm due to significant smooth muscular component of the artery along with high density of alpha- 1 adrenergic receptors, resulting in catheter entrapment. ${ }^{8,9}$

One of the first methods for the prevention of catheter looping is using preferentially the left radial artery for TR procedures especially in the elderly patients. The right subclavian tortuosity is known to be characterized as moderate twice more often in comparison with that of left side. The difference is even more prominent in octogenarians where severe tortuosity is present 5 times more 
frequently on the right side than on the left (32 vs. $6 \%, p=0.002) .{ }^{10}$ Another way of preventing severe kinking and looping is trying to avoid the rotation of the catheter for more than $180^{\circ}$. A technical suggestion is to maintain a guide wire in the catheter lumen. Another suggestion is to monitor carefully the catheter pressure tracings during manipulations. In our case, partial dampening of the pressure curve was the likely cause of severe catheter kinking. Therefore, further manipulations needs to be avoided to reduce the risk of catheter entrapment. ${ }^{11}$

The documented non-surgical techniques of unraveling a kinked \& entrapped catheter include: 1) Gentle rotation of the catheter to the opposite direction 2) Advancement of a standard 0.035 inches J wire or a super stiff wire into the loop 3) External fixation of the distal part of the catheter at the arm level both by putting circumferential pressure on the arm with the hands or with a BP cuff 4) Snare delivery 5) Long sheath technique 6) Wire-balloon aided retrieval technique 7) Sheathless guide catheter retrieval technique. ${ }^{12}$

\section{CONCLUSION:}

We need to recognize that since its introduction TR access has gained worldwide acceptance. As TR approach becomes more diffusely used, complications related to this procedure will likely be encountered more frequently. Intravascular fracture of catheters is very uncommon. Extra care should be taken when engaging an Ikari guiding catheter using the TR approach to minimize the risk of excessive twisting which may lead to catheter fracture. All retrieval techniques are part of endovascular practice \& need to be known \& applied where necessary.

\section{REFERENCES:}

1. Jolly SS, Yusuf S, Cairns J, Niemelä K, Xavier D, Widimsky $P$, et al. Radial versus femoral access for coronary angiography and intervention in patients with acute coronary syndromes (RIVAL): randomised, parallel group, multicenter trial. Lancet 2011;377:1409-20.

2. Louvard $Y$, Lefevre $T$, Allain A, Morice M. Coronary angiography through the radial or the femoral approach: the CARAFE study. Cathet Cardiovasc Diagn 2001;52:181-7.
3. Cooper CJ, El-Shiekh RA, Cohen DJ, Blaesing L, Burket MW, Basu A, et al. Effect of transradial access on quality of life and cost of cardiac catheterization: a randomized comparison. Am Heart J 1999;138:430-6.

4. Feldman DN, Swaminathan RV, Kaltenbach LA, Baklanov DV, Kim LK, Wong SC, et al. Adoption of radial access and comparison of outcomes to femoral access in percutaneous coronary intervention: an updated report from the national cardiovascular data registry (20072012). Circulation 2013;127:2295-306.

5. Resnick NJ, Kim E, Patel RS, Lookstein RA, Nowakowski FS, Fischman AM. Uterine artery embolization using a transradial approach: initial experience and technique. J Vasc Interv Radiol 2014;25:443-7.

6. Fischman AM, Swinburne NC, Patel RS. A Technical Guide Describing the Use of Transradial Access Technique for Endovascular Interventions. Tech Vasc Interv Radiol 2015; 18:58-65.

7. Kassimis G, Channon KM, Hahalis G, Poulimenos L, Manolis A, Banning AP, et al. Transradial arterial access catheter knots: how to stay out of trouble. Minerva Cardioangiol 2015;63:449-56.

8. Bertrand OF, Rao SV, Pancholy S, Jolly SS, Rodés-Cabau J, Larose $\mathrm{E}$, et al. Transradial approach for coronary angiography \& interventions: results of the first international transradial practice survey. JACC CardiovasC Interv 2010;3:1022-31.

9. Cha KS, Kim MH, Kim HJ. Prevalence \& clinical predictors of severe tortuosity of right subclavian artery in patients undergoing transradial coronary angiography. $A m \mathrm{~J}$ Cardiol 2003;92:1220-2.

10. Kallivalappil SC, Pullani AJ, Abraham B, Kumar MK, Ashraf SM. Entrapment of a transradial angiogram catheter because of severe vasospasm. J Cardiothorac Vasc Anesth 2008;22:428-30.

11. Freixa $X$, Trilla $M$, Feldman $M$, Jiménez $M$, Betriu $A$, Masotti M. Right versus left transradial approach for coronary catheterization in octogenarian patients. Catheter Cardiovasc Interv 2012;80:267-72.

12. Norgaz T, Gorgulu S, Dagdelen S. Arterial anatomic variations and its influence on transradial coronary procedur- al outcome. J Interv Cardiol 2012;25:418-24. 